\title{
Zinc supplement use and contribution to zinc intake in Australian children
}

\author{
Anna Rangan, * Aimee Jones and Samir Samman \\ Discipline of Nutrition and Metabolism, School of Molecular Bioscience G08, The University of Sydney, Sydney, \\ NSW 2006, Australia
}

Submitted 4 September 2013: Final revision received 12 February 2014: Accepted 1 April 2014: First published online 12 May 2014

\begin{abstract}
Objective: The aims of the present study were to examine the $\mathrm{Zn}$ intake and characteristics of $\mathrm{Zn}$ supplement users and non-users and to survey $\mathrm{Zn}$ supplements that are commercially available.

Design: Cross-sectional national nutrition survey (2007 Australian Children's Nutrition and Physical Activity Survey) and a review of commercially available Zn supplements.

Setting: Australia.

Subjects: Children ( $n$ 4834) aged 2-16 years.

Results: Zn supplement use was associated with younger age, being female, having a lower BMI and consuming a vegetarian or modified diet. Supplement users had significantly higher intakes of $\mathrm{Zn}$ than non-users in all age and gender subgroups. Adolescent boys aged 14-16 years who did not use Zn supplements were at highest risk of inadequate $\mathrm{Zn}$ intake (15\% compared with $1 \%$ of users). Conversely, children aged 2-3 years were at highest risk of exceeding the recommended upper limit of $\mathrm{Zn}$ intake ( $86-87 \%$ of users and $64-71 \%$ of non-users), followed by children aged 4-8 years (9-29\% of users and 3-12\% of non-users). The most common sources of $\mathrm{Zn}$ supplements consumed by children were multi-vitamin and mineral preparations (92\%), followed by Zn-only supplements (5\%) and Zn-containing cold and flu, or cold sore supplements (3\%). A survey of commercially available Zn supplements revealed that the median elemental $\mathrm{Zn}$ content was 2 and $25 \mathrm{mg}$ for multi-vitamin and mineral preparations and Zn-only supplements, respectively.

Conclusions: Based on these data, widespread $\mathrm{Zn}$ supplement use among young children is unlikely to be warranted. The impact of exceeding the upper limit of $\mathrm{Zn}$ intake on biomarkers of $\mathrm{Zn}$ toxicity requires further investigation.
\end{abstract}

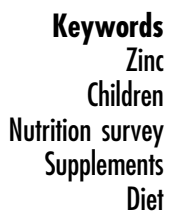

ildren Diet
Zn has a widespread role in cellular metabolic processes, immunity, neurological function and sexual development, as well as a fundamental role in growth and development ${ }^{(1,2)}$. Zn supplementation may be beneficial for those who consume low bioavailability diets that contain high levels of phytic acid, e.g. vegetarians ${ }^{(3)}$, those at risk of diarrhoeal disease ${ }^{(4)}$ and during periods of complementary feeding ${ }^{(5)}$. However, $\mathrm{Zn}$ intake above the Upper Limit (UL) increases the risk of adverse health consequences $^{(6)}$. The acute response to high $\mathrm{Zn}$ intakes may include nausea, vomiting, loss of appetite, abdominal cramps, diarrhoea and headaches ${ }^{(7)}$. If maintained for an extended period, $\mathrm{Zn}$ intake above the UL may result in decreased $\mathrm{Cu}$ absorption, altered $\mathrm{Fe}$ metabolism and reduced immune function ${ }^{(6,7)}$.

The nutrient reference values for $\mathrm{Zn}$ for Australia and New Zealand including an Estimated Average Requirement (EAR) and a $\mathrm{UL}^{(8)}$ are the same as those used in the USA but slightly different from those used in Canada ${ }^{(9)}$ and the $\mathrm{UK}^{(10)}$. The main dietary sources of $\mathrm{Zn}$ in the Australian diet include meat, poultry, dairy products and fortified cereals ${ }^{(11,12)}$.

The 2007 Australian Children's Nutrition and Physical Activity Survey (ACNPAS) is the most recent national survey of food and nutrient intake of children ${ }^{(13)}$. A secondary analysis of ACNPAS showed that boys and girls aged 2-8 years were at an increased risk of adverse health effects resulting from excessive $\mathrm{Zn}$ intake, whether from diet alone or diet plus supplements ${ }^{(12)}$. Zn supplements were used by $5.4 \%$ of children, and contributed to $2 \%$ of total $\mathrm{Zn}$ intake. While supplementary $\mathrm{Zn}$ intake was low (median intake per user was $2.0 \mathrm{mg}$ ), the $\mathrm{Zn}$ content of the supplements ranged from $0 \cdot 1$ to $129 \mathrm{mg}$. The objectives of the present paper were to elucidate these findings by: (i) examining the characteristics and $\mathrm{Zn}$ intakes of supplement users compared with non-users; and (ii) undertaking a survey of commercially available $\mathrm{Zn}$ supplements to compare $\mathrm{Zn}$ content and target audience. 


\section{Methods}

\section{Australian Children's Nutrition and Physical Activity Survey}

The 2007 ACNPAS was undertaken by the Commonwealth Scientific and Industrial Research Organisation and the University of South Australia. Permission to use data was obtained from the Australian Social Science Archives ${ }^{(14)}$. A stratified quota-sampling scheme was used to randomly select households via postcodes with children aged 2-16 years. Only one child per eligible household was selected, with the survey having a $40 \%$ response rate ${ }^{(13)}$. Data were collected from 4834 children on two separate occasions, the first using a computer-assisted personal interview and the second using a computer-assisted telephone interview. A three-pass $24 \mathrm{~h}$ recall method was used to record all foods, beverages and supplements consumed on the day prior to each interview. Both $24 \mathrm{~h}$ recalls were designed to represent different days of the week. For children aged 2-8 years, food and beverage intake was obtained from their primary caregiver. Children aged 9 years or older reported their own food and beverage intake ${ }^{(13)}$. Dietary and supplement data were translated into nutrient intake data using the survey-specific nutrient database AUSNUT $2007^{(15)}$. Data on usual diet type consumption was selfreported in response to a short question.

\section{Supplement data}

A search of Zn-containing supplements available on the Australian market was undertaken using a variety of search strategies. These included examining: (i) the AUSNUT supplement database through the Food Standards Australia and New Zealand website ${ }^{(16)}$; (ii) MIMS online ${ }^{(17)}$; (iii) the Therapeutic Goods Administration ${ }^{(18)}$; and (iv) pharmacies and product websites. Information was collected on the amount of elemental $\mathrm{Zn}$ per supplement, the presence of other vitamins and minerals, the recommended dosage as stated on the product label, the target market/consumer and the presence of any marketing claims. All Zn-containing supplements were categorised into the following groups: (i) multi-vitamin and mineral (MVM) preparations targeted at children, teens or adults; (ii) Zn-only supplements; and (iii) other Zn-containing supplements including cold and flu, and cold sore preparations (targeted at children or adults).

\section{Statistical analysis}

All dietary data collected (computer-assisted personal interview and computer-assisted telephone interview) were included in the present analysis. Total $\mathrm{Zn}$ intakes were calculated by summing $\mathrm{Zn}$ intakes from diet and supplements per person for each recall day. Total $\mathrm{Zn}$ intakes were adjusted for intra-individual variability using the Multiple Source Method (MSM) ${ }^{(19)}$ for each age and gender subgroup as specified in the nutrient reference values report for Australia and New Zealand ${ }^{(8)}$. MSM is one of several methods used to estimate usual intake distributions and has been found to produce similar results to the Iowa State University and the National Cancer Institute methods ${ }^{(20)}$. MSM uses a Box-Cox transformation to normalise intake data prior to estimating usual intake distribution. The proportions of children meeting their age- and gender-specific EAR and UL were estimated using the cut-point method ${ }^{(21)}$. Supplement users and nonusers were analysed separately. Supplement users were identified as those using a $\mathrm{Zn}$ supplement on the first, second or both days of the $24 \mathrm{~h}$ recalls.

All data were weighted to account for over- and undersampling to enable representation of the Australian population aged 2-16 years, although sample sizes are reported using unweighted data. Independent $t$ tests (for continuous data) or $\chi^{2}$ tests (for categorical data) were used to examine differences between $\mathrm{Zn}$ supplement users and non-users. ANCOVA was used to examine differences between groups while adjusting for age and gender. Analyses were conducted using the statistical software package IBM SPSS version $19 \cdot 0 . P$ values $<0.05$ were considered statistically significant.

\section{Results}

\section{Zn supplement use in the 2007 Australian Children's Nutrition and Physical Activity Survey}

$\mathrm{Zn}$ supplements were consumed during the $2 \mathrm{~d}$ of the survey by $9.4 \%$ of children using seventy-eight different supplements. Zn supplement use varied according to age, gender, BMI and usual type of diet (Table 1). Females were more likely to use a $\mathrm{Zn}$ supplement than males, and this was consistent across all age groups. Zn supplement use was higher in the younger age groups and among those who had a lower BMI. Children who consumed a modified diet such as a reduced-fat, gluten-free or low-allergen diet (16.9\%) or those who consumed a vegetarian diet (13.3\%) used $\mathrm{Zn}$ supplements to a greater extent than those who consumed a regular diet (8.6\%). Socio-economic indicators such as parental education and income were not associated with use of $\mathrm{Zn}$ supplements; neither was geographical location (urban $v$. rural) or being breast-fed (ever/never). Use of $\mathrm{Zn}$ supplements had no influence on $\mathrm{Zn}$ intake from food alone, with users and non-users having similar food-only Zn intakes (10.1 (sD 0.13) v. $10 \cdot 0$ (sD 0.04) mg/d, $P=0.36$ adjusted for age and gender). Vegetarian users and non-users also had similar $\mathrm{Zn}$ intakes from food alone (8.7 (sD 0.57) v. $8.5(\mathrm{sD} 0.27) \mathrm{mg} / \mathrm{d}, P=0.72$ adjusted for age and gender), although their total $\mathrm{Zn}$ intakes were significantly lower compared with non-vegetarians (8.7 (SD $0 \cdot 29) v \cdot 10.3(\mathrm{sD} 0.05) \mathrm{mg} / \mathrm{d}, P<0.001$, adjusted for age and gender).

Supplement users had significantly higher mean intakes of $\mathrm{Zn}$ than non-users in all age and gender subgroups (Table 2). Nearly all children aged $2-13$ years met the EAR 
Table 1 Demographic data for zinc supplement users and non-users among Australian children ( $n$ 4834) aged 2-16 years; 2007 Australian Children's Nutrition and Physical Activity Survey

\begin{tabular}{|c|c|c|c|c|c|}
\hline \multirow[b]{2}{*}{ Characteristic } & \multicolumn{2}{|c|}{ Supplement user } & \multicolumn{2}{|c|}{ Supplement non-user } & \multirow[b]{2}{*}{$P$ value } \\
\hline & Mean or $\%$ & $n$ or SD & Mean or $\%$ & $n$ or SD & \\
\hline$n \dagger$ & - & 416 & - & 4418 & \\
\hline Age (years) & 8.4 & 4.3 & $9 \cdot 1$ & 4.3 & 0.001 \\
\hline BMI $\left(\mathrm{kg} / \mathrm{m}^{2}\right) \ddagger$ & $18 \cdot 2$ & $3 \cdot 3$ & $18 \cdot 6$ & 3.8 & 0.015 \\
\hline \multicolumn{6}{|l|}{ Gender (\%) } \\
\hline Male & $8 \cdot 3$ & - & 91.7 & - & 0.015 \\
\hline Female & $10 \cdot 4$ & - & 89.6 & - & \\
\hline \multicolumn{6}{|l|}{ Usual diet (\%) } \\
\hline No special diet & $8 \cdot 6$ & - & 91.4 & - & $<0.001$ \\
\hline Vegetarian & $13 \cdot 3$ & - & $86 \cdot 7$ & - & \\
\hline Modified diet§ & $16 \cdot 9$ & - & 83.1 & - & \\
\hline
\end{tabular}

†Unweighted sample size.

$\ddagger$ Adjusted for age and gender.

$\S$ Weight-reduction, fat modification or diabetic diet.

Table 2 Zinc intake† (mg/d) and dietary adequacy by zinc supplement user status among Australian children $(n$ 4834) aged 2-16 years; 2007 Australian Children's Nutrition and Physical Activity Survey

\begin{tabular}{|c|c|c|c|c|c|c|c|c|}
\hline & \multirow[b]{2}{*}{$n \ddagger$} & \multirow[b]{2}{*}{ Zn supplement user } & \multicolumn{2}{|c|}{ Zn intake $(\mathrm{mg} / \mathrm{d})$} & \multirow[b]{2}{*}{$\operatorname{EAR}(\mathrm{mg} / \mathrm{d})$} & \multirow[b]{2}{*}{$\%<\mathrm{EAR}$} & \multirow[b]{2}{*}{$\mathrm{UL}(\mathrm{mg} / \mathrm{d})$} & \multirow[b]{2}{*}{$\%>$ UL } \\
\hline & & & Mean & SD & & & & \\
\hline \multicolumn{9}{|l|}{ Boys } \\
\hline \multirow[t]{2}{*}{ 2-3 years } & 576 & No & $8 \cdot 1^{*}$ & 1.7 & $2 \cdot 5$ & 0 & 7 & 71.4 \\
\hline & 46 & Yes & $9 \cdot 4$ & $2 \cdot 7$ & 2.5 & 0 & 7 & $87 \cdot 3$ \\
\hline \multirow[t]{2}{*}{$4-8$ years } & 570 & No & $9 \cdot 8^{*}$ & 1.9 & 3 & 0 & 12 & $12 \cdot 2^{*}$ \\
\hline & 70 & Yes & 11.3 & 2.6 & 3 & 0 & 12 & $29 \cdot 1$ \\
\hline \multirow{2}{*}{$9-13$ years } & 539 & No & $11 \cdot 7^{*}$ & 2.4 & 5 & 0 & 25 & 0 \\
\hline & 40 & Yes & $13 \cdot 4$ & $2 \cdot 9$ & 5 & 0 & 25 & 0.8 \\
\hline \multirow[t]{2}{*}{$14-16$ years } & 559 & No & $14 \cdot 9^{*}$ & $4 \cdot 2$ & 11 & $14 \cdot 6^{*}$ & 35 & 0 \\
\hline & 37 & Yes & 18.9 & $6 \cdot 2$ & 11 & 1.0 & 35 & 0 \\
\hline \multicolumn{9}{|l|}{ Girls } \\
\hline \multirow{2}{*}{ 2-3 years } & 514 & No & $7 \cdot 8^{*}$ & 1.9 & $2 \cdot 5$ & 0 & 7 & $64.4^{*}$ \\
\hline & 55 & Yes & $9 \cdot 2$ & 3.2 & $2 \cdot 5$ & 0 & 7 & 86.5 \\
\hline \multirow[t]{2}{*}{$4-8$ years } & 548 & No & $8 \cdot 6^{*}$ & 1.6 & 3 & 0 & 12 & $3 \cdot 1^{*}$ \\
\hline & 75 & Yes & 9.5 & $2 \cdot 3$ & 3 & 0 & 12 & $9 \cdot 4$ \\
\hline \multirow[t]{2}{*}{$9-13$ years } & 591 & No & $10 \cdot 2^{*}$ & 2.4 & 5 & 0.5 & 25 & 0 \\
\hline & 49 & Yes & 11.1 & 3.1 & 5 & 0 & 25 & 0 \\
\hline \multirow[t]{2}{*}{$14-16$ years } & 521 & No & $10 \cdot 0^{*}$ & 2.6 & 6 & 5.4 & 35 & 0 \\
\hline & 44 & Yes & 14.4 & 5.7 & 6 & 0 & 35 & 0 \\
\hline
\end{tabular}

EAR, Estimated Average Requirement; UL, Upper Limit.

${ }^{*} P<0.05$ between $\mathrm{Zn}$ supplement users and non-users.

†Adjusted using the Multiple Source Method by age and gender subgroup.

‡Unweighted sample size.

for $\mathrm{Zn}$, regardless of supplemental $\mathrm{Zn}$ intake. Boys aged 14-16 years who did not use $Z n$ supplements were at highest risk of inadequate $\mathrm{Zn}$ intake (14.6\%).

Conversely, children at highest risk of exceeding the UL for $\mathrm{Zn}$ were those aged $2-3$ years, with $86 \cdot 5-87 \cdot 3 \%$ of supplement users and $64 \cdot 4-71.4 \%$ of non-users consuming amounts above the UL. A significant proportion of children aged 4-8 years also consumed $\mathrm{Zn}$ above the UL, in particular those who used $\mathrm{Zn}$ supplements (9.4-29.1\%).

The most common $\mathrm{Zn}$ supplements used by children in the survey were MVM preparations ( $92 \%$ ), followed by Zn-only supplements (5\%) and other supplements such as cold and flu, and cold sore tablets (3\%). The majority of these supplements contained 1-2 mg Zn. However, eighteen children aged 2-3 years and four children aged 4-8 years consumed a supplement that exceeded the UL for Zn.

\section{Commercially available Zn supplements}

We identified sixty-seven types of MVM preparations (twenty-three for children, six for teens and thirty-eight for adults), fourteen varieties of Zn-only supplements and ten other Zn-containing supplements (three for children and seven for adults; see online supplementary material, Supplementary Tables 1-6). The median elemental Zn content of supplements ranged from $2 \mathrm{mg}$ in children's MVM to $25 \mathrm{mg}$ for Zn-only supplements, and three preparations were found to contain $<0.1 \mathrm{mg}$ elemental Zn (Table 3). 
Table 3 Elemental zinc content $(\mathrm{mg})$ of zinc-containing commercially available supplements, Australia

\begin{tabular}{|c|c|c|c|c|c|c|}
\hline \multirow[b]{2}{*}{ Supplement type } & \multirow[b]{2}{*}{$n$} & \multicolumn{2}{|c|}{ Zn content (mg) } & \multirow[b]{2}{*}{ Median } & \multirow[b]{2}{*}{ Minimum } & \multirow[b]{2}{*}{ Maximum } \\
\hline & & Mean & SD & & & \\
\hline \multicolumn{7}{|l|}{ MVM } \\
\hline Children & 23 & $2 \cdot 7$ & 2.5 & $2 \cdot 0$ & 0.1 & $8 \cdot 2$ \\
\hline Teens & 6 & $14 \cdot 3$ & 1.6 & $15 \cdot 0$ & $11 \cdot 0$ & $15 \cdot 0$ \\
\hline Adults & 38 & $8 \cdot 7$ & $5 \cdot 5$ & $6 \cdot 5$ & 1.0 & $20 \cdot 0$ \\
\hline \multicolumn{7}{|l|}{ Zn-only } \\
\hline Adults/children & 14 & $24 \cdot 2$ & 11.6 & $25 \cdot 0$ & $5 \cdot 7$ & 49.5 \\
\hline \multicolumn{7}{|l|}{ Other† } \\
\hline Children & 3 & $2 \cdot 8$ & $2 \cdot 0$ & 2.5 & 1.0 & $5 \cdot 0$ \\
\hline Adults & 7 & $7 \cdot 4$ & 8.4 & $5 \cdot 0$ & 1.3 & $25 \cdot 0$ \\
\hline
\end{tabular}

MVM, multi-vitamin and mineral preparations.

†Includes $\mathrm{Zn}$-containing cold and flu supplements and cold sore supplements.

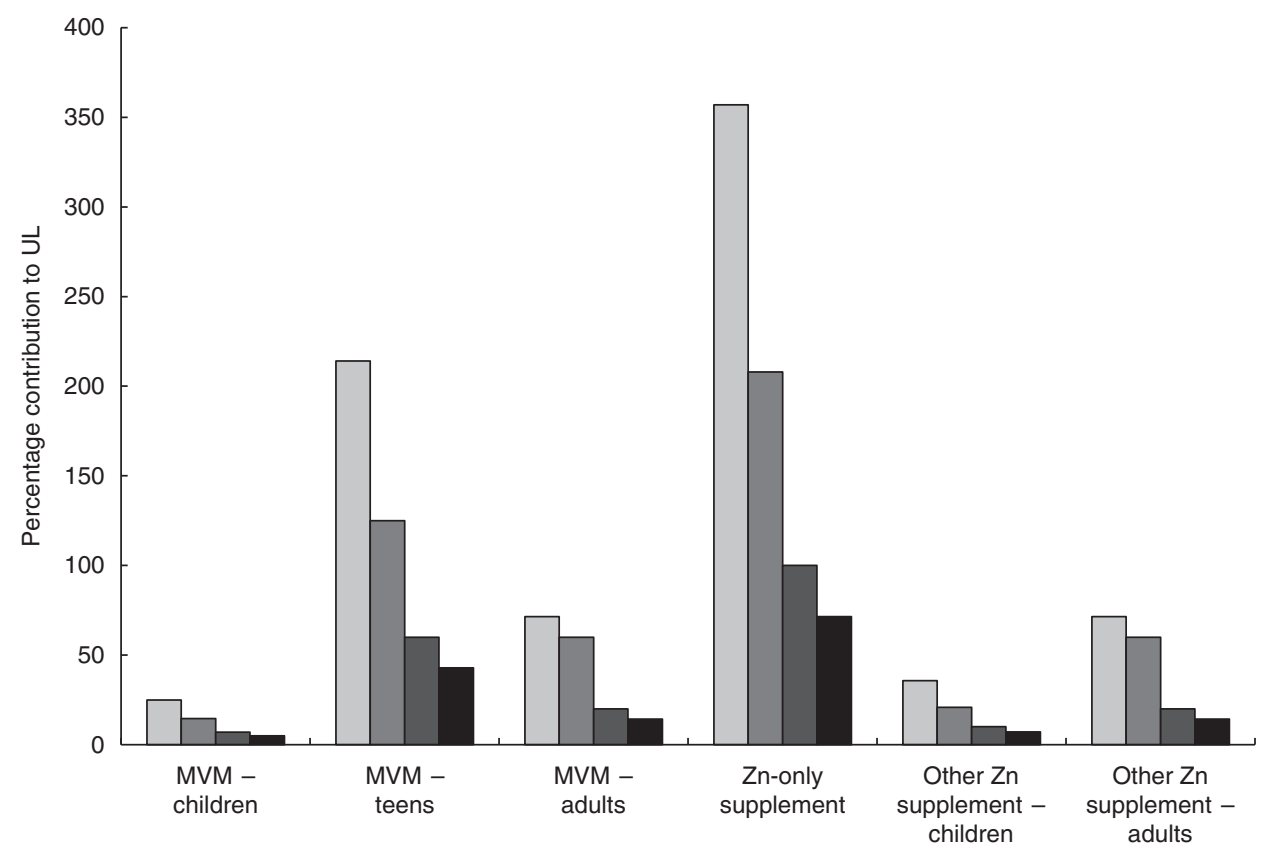

Fig. 1 Contribution of supplemental zinc (median, mg) to the Upper Limit (UL) for zinc by age group ( $\square$, 2-3 years; $\square$, 4-8 years; $\square$, 9-13 years; $\square, 14-16$ years) among Australian children ( $n$ 4834) aged 2-16 years; 2007 Australian Children's Nutrition and Physical Activity Survey (MVM, multi-vitamin and mineral preparations)

Figure 1 illustrates the contribution of the median amount of supplemental $\mathrm{Zn}$ relative to the UL. For children aged 2-3 years, the consumption of any Zn-containing supplement contributes at least $25 \%$ to the UL and consumption of MVM preparations for teens or Zn-only supplements would exceed the UL by $200 \%$ and $350 \%$, respectively. Similarly, for children aged 4-8 years, the use of MVM preparations for teens or a Zn-only supplement would exceed the UL, as would a Zn-only supplement for children aged 9-13 years.

Examination of supplement labels reveals a wide range of marketing claims (Supplementary Tables 1-6). The most common claims used on MVM supplement labels were to promote normal growth, improve health, well-being, and immunity. Zn-only supplements targeted at those $>12$ years claimed to aid in wound healing, reproductive health and immune function. Frequently stated claims on cold and flu tablets promoted the products for reducing the severity and duration of the common cold and for boosting immune function.

\section{Discussion}

The results of the ACNPAS show that use of Zn-containing supplements was relatively infrequent but was dependent on age, gender, BMI and habitual diet. Those being younger, female, of lower BMI and consuming a vegetarian or modified diet were more likely to use a $\mathrm{Zn}$ supplement than their counterparts. Supplement users had higher $\mathrm{Zn}$ intakes than non-users in all age and gender subgroups. $\mathrm{Zn}$ requirements (EAR) were met by most children regardless of supplement usage, with the exception of boys aged 
14-16 years who did not use a Zn supplement. In contrast, a high percentage of children aged $2-3$ years and $4-8$ years exceeded the UL, particularly among supplement users.

Supplement use among children has been examined in recent surveys conducted in the USA, Canada, Australia and European countries, with prevalence rates approximating $25-45 \%$ in children and $15-30 \%$ in adolescents. In general, prevalence rates were higher among younger children than pre-adolescents and adolescents ${ }^{(22-29)}$. Supplement use among children has been characterised by high parental education and income levels, having better nutrient intakes, lower prevalence of overweight and obesity and having a healthier lifestyle $\mathrm{e}^{(22,26,28,30)}$. Parental use of supplements has also been associated with supplement use by their children $^{(25)}$. In our study, users had lower BMI but no differences were observed in terms of parental education and income compared with non-users. In addition, users and non-users of $\mathrm{Zn}$ supplements had similar $\mathrm{Zn}$ intakes from food alone, suggesting that supplemental $\mathrm{Zn}$ intake was taken in addition to and not replacing dietary intake. Most studies have reported similar or higher food-only $\mathrm{Zn}$ intakes in supplement users compared with non-users ${ }^{(23-25,28,31,32)}$.

MVM supplements are the most commonly used type of dietary supplement ${ }^{(27,29,33)}$ and the vast majority of children in our survey who used supplements, took MVM supplements. Zn-only supplements and other dietary $\mathrm{Zn}$ supplements were used by less than $10 \%$ of those who took supplements. Users of Zn supplements had higher total $\mathrm{Zn}$ intakes than non-users, which is consistent with other large-scale surveys ${ }^{(23-25,27,28)}$.

Our results revealed that food alone was sufficient to meet the EAR for all children's age/gender groups, except for adolescent boys aged 14-16years. This group has the highest $\mathrm{Zn}$ requirement $(\mathrm{EAR}=11 \mathrm{mg} / \mathrm{d})$ and $15 \%$ of boys were unable to meet this requirement without the use of a $\mathrm{Zn}$ supplement. These results are comparable to those of the US National Health and Nutrition Examination Survey (NHANES) 2003-2006, which found 14-18-yearolds who did not use a dietary supplement had the highest prevalence of inadequate $\mathrm{Zn}$ intake but results were not specified for males and females ${ }^{(25)}$. In a national Canadian study, adolescent girls were most at risk of inadequate intakes ${ }^{(23)}$ but as recommended $\mathrm{Zn}$ requirements ${ }^{(9)}$ are slightly different from those in the USA and Australia, these results are not directly comparable.

Children who followed vegetarian diets had lower $\mathrm{Zn}$ intakes but higher supplement use compared with nonvegetarian children. A recent meta-analysis examining $\mathrm{Zn}$ intakes found that dietary $\mathrm{Zn}$ intakes were significantly lower by $0.9 \mathrm{mg} / \mathrm{d}$ in populations that followed habitual vegetarian diets compared with non-vegetarians ${ }^{(3)}$. Although the number of vegetarians in our survey was relatively small, those who used supplements were better able to meet their $\mathrm{Zn}$ requirements, especially adolescents.

Supplement use among toddlers and pre-school children has been associated with a higher prevalence of exceeding the UL in other international surveys. Analysis from the NHANES 2003-2006 with 7250 children (2-18 years) found that those who used supplements (23-44\% depending on age/gender group) had a higher prevalence of exceeding the UL for $\mathrm{Zn}$. This was most pronounced in the youngest age groups; $2-8$ years ( $84 \% v .45 \%), 9-13$ years $(32 \% v .<1 \%)$, $14-18$ years $(8 \% v .<1 \%)^{(25)}$. The Feeding Infants and Toddlers Study including 3022 US infants and toddlers found that high proportions of users of vitamin/mineral supplements had $\mathrm{Zn}$, as well as vitamin $\mathrm{A}$ and folate intakes exceeding the $\mathrm{UL}^{(24)}$. For toddlers aged 12-24 months, $68 \%$ of supplement users and $38 \%$ of non-users had $\mathrm{Zn}$ intakes above the UL while less than $1 \%$ of toddlers (users and nonusers) had an inadequate EAR for $\mathrm{Zn}$. The authors concluded that in general, healthy infants and toddlers can achieve recommended levels of nutrient intakes from foods alone and care must be taken with supplements to ensure that the doses do not lead to intakes above the UL, especially for nutrients that are widely used as food fortificants ${ }^{(24)}$.

Even without accounting for supplemental $\mathrm{Zn}$, the prevalence of exceeding the UL for young children is high. The 1994-1996 and 1998 Continuing Survey of Food Intakes by Individuals (CSFII), which examined nutrient intakes of 7474 US children aged less than 6 years, found that the percentage of children exceeding the UL for $\mathrm{Zn}$ intake to be $92 \%$ in the $0-6$ months age group, $86 \%$ in the $7-12$ months age group, $51 \%$ in the $1-3$ years age group and $3 \%$ in those aged $4-5$ years ${ }^{(34)}$. The high intakes of $\mathrm{Zn}$ among children in the USA have been attributed to food fortification $^{(35,36)}$

Adverse effects such as nausea, vomiting, loss of appetite, abdominal cramps, diarrhoea, headaches, decreased $\mathrm{Cu}$ absorption, altered Fe function and reduced immune function have been associated with excessive supplementation of $\mathrm{Zn}^{(6)}$. These data were obtained mainly from adults and it has been suggested that $\mathrm{Zn}$ intakes above the UL in children should not be a cause for concern because the data are limited, and there is little documentation of adverse effects in children $^{(37)}$. In support of this notion, a recent study investigated the effects of $\mathrm{Zn}$ supplements on adverse effects among young children ${ }^{(38)}$. Healthy 6-8-year-old boys consumed $\mathrm{Zn}$ supplements ranging from 5 to $15 \mathrm{mg}$ elemental $\mathrm{Zn}$ daily in addition to habitual $\mathrm{Zn}$ intakes from food that approached or in some instances exceeded the UL. After 4 months of supplementation, biomarkers of $\mathrm{Cu}$ status were unaffected by $\mathrm{Zn}$ supplementation. The authors of this trial highlight the need for the examination of the current UL for Zn for children ${ }^{(37,38)}$.

While the Zn content of most commercially available $\mathrm{Zn}$ supplements is below the UL of $\mathrm{Zn}$ intake for most age groups, the recommended number of tablets suggested to be consumed for each age group must also be considered. Consuming one MVM or cold and flu tablet will generally not cause $\mathrm{Zn}$ intake to exceed the UL. However, the consumption of multiple doses or Zn-only products in addition to the dietary intake may increase $\mathrm{Zn}$ intake to 
levels above the UL. The Maximum Recommended Daily Dose for Zn set by the Therapeutic Goods Administration in Australia is $50 \mathrm{mg}^{\text {(39) }}$, well above the UL for children as well as adults. Similar limits have been set in Canada and the UK has a safe upper limit for supplemental $\mathrm{Zn}$ of $25 \mathrm{mg}^{(40,41)}$. Lower limits of $10-15 \mathrm{mg} \mathrm{Zn}$ maximum per supplement have been proposed by the European Union ${ }^{(42)}$.

There may be some therapeutic advantages of using $\mathrm{Zn}$ supplements. The use of $\mathrm{Zn}$ supplements for preventing or treating the common cold has been investigated in recent reviews. Zn administered at doses $\geq 75 \mathrm{mg} / \mathrm{d}$ within $24 \mathrm{~h}$ of onset of symptoms was found to reduce the duration of common cold symptoms in healthy adults ${ }^{(43)}$. Another systematic review also found beneficial effects of $\mathrm{Zn}$ supplementation among adults but not among children ${ }^{(44)}$. Although there is little evidence for a beneficial effect for children in developed countries, Zn supplementation may be of benefit for children in developing countries in lowering rates of acute lower respiratory infections ${ }^{(45)}$.

The limitations of the present study must be acknowledged. The 2007 ACNPAS used a complex sample design involving stratification, a high degree of clustering and estimation weights. Children residing in very remote areas or in households without a fixed telephone line were not included in the survey. Although survey weights (accounting for age, gender and stratum/location) were applied, prevalence estimates may still be biased and not completely representative of the Australian population. The sample of participants using Zn supplements was relatively small although significant differences were detected between users and non-users. Supplements may be taken irregularly and data collected over a short period of time may not have provided an accurate reflection of usual practices ${ }^{(46)}$ and the type/ form of $\mathrm{Zn}$ in each supplement was not collected. All $\mathrm{Zn}$ supplements were included in the current analysis despite the content of $\mathrm{Zn}$; and information on commercially available supplements such as dosage, claims and consumer targets may have changed since our survey of the market.

\section{Conclusion}

In conclusion, analysis of the 2007 ACNPAS shows that the use of $\mathrm{Zn}$ supplements resulted in a high prevalence of children who had intakes above the UL. In particular for children aged 2-3 years, supplement use led to excessive intakes of $\mathrm{Zn}$. The vast majority of children met the recommended intake targets by food intake alone with the exception of 14-16-year-old boys. Further investigation of the $\mathrm{Zn}$ status of Australian children is needed, including the assessment of $\mathrm{Zn}$ biomarkers.

\section{Acknowledgements}

Financial support: This research received no specific grant from any funding agency in the public, commercial or not-for-profit sectors. Conflict of interest: None. Authorship: A.R. and S.S. formulated the research question, A.R. analysed the data, A.J. collated data on commercially available supplements and all authors contributed to the writing of the article. Ethics of buman subject participation: Ethics approval for the 2007 Australian Children's Nutrition and Physical Activity Survey covering ethical, privacy and confidentiality was obtained from the National Health and Medical Research Council-registered Ethics Committees of the Commonwealth Scientific and Industrial Research Organisation and the University of South Australia.

\section{Supplementary material}

To view supplementary material for this article, please visit http://dx.doi.org/10.1017/S1368980014000871

\section{References}

1. King JC \& Cousins RJ (2006) Zinc. In Modern Nutrition in Health and Disease, 10th ed., pp. 271-285 [ME Shils, M Shike, AC Ross et al., editors]. Philadelphia, PA: Lippincott Williams \& Wilkins.

2. Samman S (2007) Zinc. Nutr Diet 64, Suppl. S4, S131-S134.

3. Foster M, Chu A, Petocz P et al. (2013) Effect of vegetarian diets on zinc status: a systematic review and meta-analysis of studies in humans. J Sci Food Agric 93, 2362-2371.

4. Brown KH, Peerson JM, Baker SK et al. (2009) Preventive zinc supplementation among infants, preschoolers, and older prepubertal children. Food Nutr Bull 30, 1 Suppl., S12-S40.

5. Allen L (1998) Zinc and micronutrient supplements for children. Am J Clin Nutr 68, 495-498.

6. Institute of Medicine, Food and Nutrition Board (2001) Dietary Reference Intakes for Vitamin A, Vitamin K, Arsenic, Boron, Chromium, Copper, Iodine, Iron, Manganese, Molybdenum, Nickel, Silicon, Vanadium and Zinc. Washington, DC: National Academy Press.

7. Samman S \& Roberts DC (1987) The effect of zinc supplements on plasma zinc and copper levels and the reported symptoms in healthy volunteers. Med J Aust 146, 246-249.

8. National Health and Medical Research Council (2006) Nutrient Reference Values for Australia and New Zealand. Canberra: Commonwealth of Australia.

9. Health Canada (2010) Dietary Reference Intakes Tables. Ottawa: Health Canada.

10. Committee on Medical Aspects of Food Policy (1991) Dietary Reference Values for Food Energy and Nutrients for the United Kingdom. London: HMSO.

11. McLennan W \& Podger A (1998) National Nutrition Survey 1995: Nutrient Intakes and Physical Measurements. ABS Catalogue no. 4805.0. Canberra: ABS.

12. Rangan A \& Samman S (2012) Zinc intake and its dietary sources: results of the 2007 Australian National Children's Nutrition and Physical Activity Survey. Nutrients 4, 611-624.

13. Department of Health and Ageing (2008) The 2007 Australian National Children's Nutrition and Physical Activity Survey - User Guide. Canberra: Commonwealth of Australia.

14. Australian Social Science Data Archive (2009) The 2007 National Children's Nutrition and Physical Activity Survey. http://www.assda.edu.au (accessed August 2009).

15. Food Standards Australia New Zealand (2007) AUSNUT 2007. Canberra: FSANZ. 
16. Food Standards Australia New Zealand (2007) Supplement File. Canberra: FSANZ.

17. MIMS Australia (2013) MIMS online. Sydney: MIMS.

18. Department of Health and Ageing (2013) Therapeutic Goods Administration (TGA). Canberra: Department of Health and Ageing.

19. Harttig U, Haubrock J, Knuppel $S$ et al:; EFCOVAL Consortium (2011) The MSM program: web-based statistics package for estimating usual dietary intake using the Multiple Source Method. Eur J Clin Nutr 65, Suppl. 1, S87-S91.

20. Souverein OW, Dekkers AL, Geelen A et al. (2011) Comparing four methods to estimate usual intake distributions. Eur J Clin Nutr 65, Suppl. 1, S92-S101.

21. Food and Nutrition Board, Institute of Medicine (2001) DRI Dietary Reference Intakes: Applications in Dietary Assessment. Washington, DC: National Academy Press.

22. Sichert-Hellert W \& Kersting M (2004) Vitamin and mineral supplements use in German children and adolescents between 1986 and 2003: results of the DONALD Study. Ann Nutr Metab 48, 414-419.

23. Shakur YA, Tarasuk V, Corey P et al. (2012) A comparison of micronutrient inadequacy and risk of high micronutrient intakes among vitamin and mineral supplement users and nonusers in Canada. J Nutr 142, 534-540.

24. Briefel R, Hanson C, Fox MK et al. (2006) Feeding Infants and Toddlers Study: do vitamin and mineral supplements contribute to nutrient adequacy or excess among US infants and toddlers? I Am Diet Assoc 106, 1 Suppl. 1, S52-S65.

25. Bailey RL, Fulgoni VL III, Keast DR et al. (2012) Do dietary supplements improve micronutrient sufficiency in children and adolescents? J Pediatr 161, 837-842.

26. Dwyer J, Nahin RL, Rogers GT et al. (2013) Prevalence and predictors of children's dietary supplement use: the 2007 National Health Interview Survey. Am J Clin Nutr 97, 1331-1337.

27. Bates B, Lennox A, Prentice A et al. (2013) National Diet and Nutrition Survey; Headline results from years 1,2 and 3 (combined) of the Rolling Programme (2008/2009-2010/ 2011). https://www.gov.uk/government/uploads/system/ uploads/attachment_data/file/207708/NDNS-Y3-report_AllTEXT-docs-combined.pdf (accessed August 2013).

28. Huybrechts I, Maes L, Vereecken C et al. (2010) High dietary supplement intakes among Flemish preschoolers. Appetite 54, 340-345.

29. Commonwealth Scientific and Industrial Research Organisation (2012) The 2007 Australian National Children's Nutrition and Physical Activity Survey. vol. 3: Dietary Supplements Consumed. Canberra: Department of Health and Ageing.

30. Reaves L, Steffen LM, Dwyer JT et al. (2006) Vitamin supplement intake is related to dietary intake and physical activity: the Child and Adolescent Trial for Cardiovascular Health (CATCH). J Am Diet Assoc 106, 2018-2023.

31. Bailey R, Fulgoni V III, Keast D et al. (2011) Dietary supplement use is associated with higher intakes of minerals from food sources. Am J Clin Nutr 94, 1376-1381.

32. Murphy SP, White KK, Park SY et al. (2007) Multivitaminmultimineral supplements' effect on total nutrient intake. Am J Clin Nutr 85, issue 1, 280S-284S.

33. Picciano MF, Dwyer JT, Radimer KL et al. (2007) Dietary supplement use among infants, children, and adolescents in the United States, 1999-2002. Arch Pediatr Adolesc Med 161, 978-985.

34. Arsenault J \& Brown K (2003) Zinc intake of US preschool children exceeds new Dietary Reference Intakes (DRIs). Am J Clin Nutr 78, 1011-1017.

35. Fulgoni VL 3rd, Keast DR, Bailey RL et al. (2011) Foods, fortificants, and supplements: where do Americans get their nutrients? J Nutr 141, 1847-1854.

36. Sacco JE, Dodd KW, Kirkpatrick SI et al. (2013) Voluntary food fortification in the United States: potential for excessive intakes. Eur J Clin Nutr 67, 592-597.

37. Zlotkin S (2006) A critical assessment of the upper intake levels for infants and children. J Nutr 136, 502-506.

38. Bertinato J, Simpson JR, Sherrard L et al. (2013) Zinc supplementation does not alter sensitive biomarkers of copper status in healthy boys. J Nutr 143, 284-289.

39. Therapeutic Goods Administration (2007) Substances That May be Used in Listed Medicines in Australia. Canberra: TGA.

40. Health Canada (2007) Natural Health Products Ingredients Database: Multi-Vitamin/Mineral Supplements. Ottawa: Health Canada.

41. Expert Group on Vitamins and Minerals (2003) Safe Upper Levels for Vitamins and Minerals. London: Food Standards Agency.

42. European Commission, Directorate-General for Health and Consumer Protection (2006) Discussion Paper on the Setting of Maximum and Minimum Amounts for Vitamins and Minerals in Foodstuffs. Brussels: European Commission.

43. Singh M \& Das RR (2013) Zinc for the common cold. Cochrane Database Syst Rev 6, CD001364.

44. Science M, Johnstone J, Roth D et al. (2012) Zinc for the treatment of the common cold: a systematic review and metaanalysis of randomized controlled trials. CMAJ 184, E551-E561.

45. Roth D, Richard S \& Black R (2010) Zinc supplementation for the prevention of acute lower respiratory infection in children in developing countries: meta-analysis and metaregression of randomized trials. Int J Epidemiol 39, 795-808.

46. Dwyer J, Picciano MF, Raiten D et al. (2003) Collection of food and dietary supplement intake data: What We Eat in America-NHANES. J Nutr 133, issue 2, 590S-600S. 